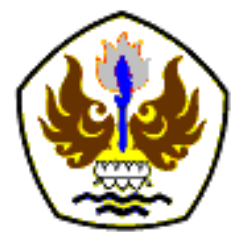

INFOMATEK

Volume 21 Nomor 1 Juni 2019

\title{
UJI EFEKTIVITAS IONIZER BBM TERHADAP PENURUNAN EMISI GAS KARBON MONOKSIDA DAN HIDROKARBON PADA MOBIL DENGAN SISTEM KARBURATOR
}

\author{
Lili Mulyatna"), Yonik Meilawati Yustiani, Ahmad M. Sidik \\ Program Studi Teknik Lingkungan \\ Fakultas Teknik - Universitas Pasundan
}

\begin{abstract}
Abstrak: Salah satu sumber pencemaran udara di kota besar adalah emisi gas buang yang berasal dari kendaraan. Untuk mengurangi emisi gas buang tersebut, alternatif yang sering digunakan adalah ionizer bahan bakar minyak (BBM) yang pada prinsipnya dapat meningkatkan pembakaran. Penelitian ini bertujuan untuk mengetahui tingkat efektifitas penggunaan ionizer BBM tersebut untuk mengurangi emisi gas karbon monoksida (CO) dan hidrokarbon (HC) dari proses pembakaran BBM jenis Premium, Pertalite dan Pertamax. Alat yang digunakan untuk mengukur emisi gas buang adalah exhaust gas analyzer, sedangkan kendaraan bermotor yang digunakan adalah mobil dengan sistem karburator. Hasil pengukuran emisi $\mathrm{CO}$ dan $\mathrm{HC}$ tersebut kemudian diolah untuk mengetahui tingkat efektivitas ionizer BBM. Hasil pengolahan data memperlihatkan bahwa ionizer BBM memiliki efisiensi penurunan emisi yang berbeda-beda untuk tiap jenis bahan bakar. Penurunan emisi gas $\mathrm{CO}$ paling tinggi terjadi pada bahan bakar pertamax sebesar $0,31 \%$, sedangkan penurunan emisi gas HC mencapai sebesar 347,66 ppm. Hasil tersebut memperlihatkan bahwa efektifitas ionizer BBM dalam mengurangi emisi CO dan $\mathrm{HC}$ relatif rendah.
\end{abstract}

Kata kunci: Emisi CO dan HC, lonizer BBM, Mobil sistem Karburator

\section{PENDAHULUAN}

Kota-kota besar di Indonesia mengalami pencemaran udara yang buruk akibat emisi gas buang kendaraan bermotor yang semakin meningkat jumlahnya. Diperkirakan pada tahun 2020, setengah dari populasi di Indonesia akan menghadapi masalah pencemaran emisi gas buang dari kendaraan

*) lili.mulyatna@gmail.com

Pertama diterima : 20 Maret 2019

Direvisi : 13 April 2019

Disetujui untuk publikasi: 31 Mei 2019 bermotor, terutama gas karbon monoksida (CO) dan hidrokarbon (HC) (Gunawan [1]). Tingginya konsentrasi emisi gas buang ini disebabkan karena tidak sempurnanya pembakaran yang terjadi dalam mesin kendaraan bermotor (Yahya [2]). Pencemaran udara akibat emisi gas buang kendaraan bermotor ini dapat mengakibatkan penurunan kesehatan (Ismiyati, dkk. [3]). Gas karbon monoksida dapat menurunkan kemampuan darah manusia dalam mengikat oksigen (Dahlan [4]) dan disebut sebagai racun syaraf 
([5]). Sedangkan hidrokarbon jika bercampur dengan pencemar lain dapat berbentuk PAH (Polyciclic Aromatic Hydrocarbon) yang berpotensi menstimulasi munculnya sel kanker jika terhirup (Sugiarti [6]). Selain berdampak terhadap kesehatan manusia, gas buang kendaraan bermotor juga mengakibatkan kerusakan pada lingkungan, baik biota maupun abiota [4].

Salah satu cara teknologi yang ditawarkan perusahaan otomotif untuk menurunkan emisi gas buang kendaraan bermotor adalah ionizer BBM (bahan bakar minyak). Ionizer BBM ini berfungsi untuk meningkatkan proses pembakaran agar lebih sempurna dengan cara menjadikan molekul bahan bakar bermuatan positif sehingga mengikat oksigen lebih baik (https://xpower-ionizer.com [7]).

Saat ini, masyarakat masih banyak yang menggunakan jenis mobil dengan sistem karburator. Pencampuran bahan bakar dengan udara pada jenis mobil ini kurang sempurna sehingga menimbulkan emisi gas buang yang lebih banyak jika dibandingkan dengan mobil sistem injeksi. Hal ini juga mengakibatkan penggunaan bahan bakar yang lebih banyak untuk mobil sistem karburator (Santoso [8]). Kondisi menjadikan alasan kuat penggunaan ionizer BBM untuk mobil-mobil sistem karburator. Variasi bahan bakar yang populer digunakan oleh masyarakat yaitu produksi Pertamina berupa Premium, Pertalite dan Pertamax (Mulyono, dkk. [9], Luthfi, dkk. [10]).

Penelitian ini bertujuan untuk mengukur tingkat efektivitas penggunaan ionizer BBM pada mobil sistem karburator dengan jenis bahan bakar Premium, Pertalite dan Pertamax dalam mengurangi emisi gas buang berupa karbon monoksida dan hidrokarbon. Hasil penelitian ini dapat digunakan untuk pengambilan keputusan bagi pemilik mobil dalam menentukan penggunaan ionizer BBM tersebut.

\section{METODOLOGI}

\subsection{Lokasi Penelitian}

Penelitian terhadap efektivitas ionizer BBM ini dilakukan di bengkel Nusantara Jaya Sentosa yang memenuhi syarat sebagai pemeriksa uji emisi resmi oleh pemerintah Kota Bandung berdasarkan Peraturan Walikota Bandung No. 5/2010 tentang Pengujian Ambang Batas Emisi Gas Buang Kendaraan Bermotor. Persyaratan bagi pengujian ini meliputi administrasi dan teknik.

\subsection{Alat dan Bahan}

Alat serta bahan yang menunjang pada kajian ini antara lain :

1. Exhaust Gas Analyzer; yaitu alat yang berfungsi untuk mengukur kandungan gas buang melalui saluran buang 
(exhaust monifold) pada kendaraan bermotor. Alat yang digunakan saat penelitian berupa gas analyzer merk Heshbon model HG-520. Gambar 1 memperlihatkan alat gas analyzer yang digunakan tersebut.

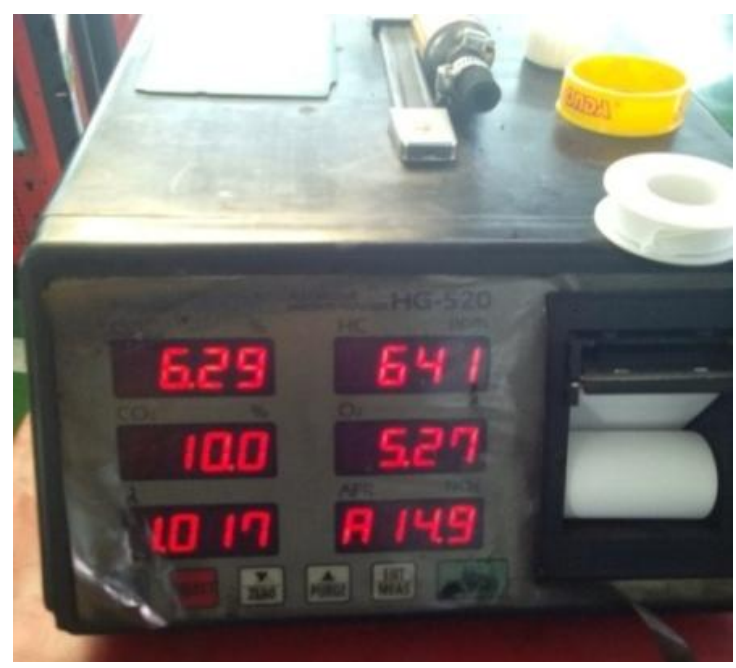

Gambar 1.

Gas Analyzer Merk Heshbon Model HG-520.

2. Ionizer BBM; yaitu sebuah alat yang berfungsi untuk mengionisasi molekul pada BBM menjadi ion, sehingga dapat mengikat oksigen lebih sempurna. Ionizer BBM yang digunakan dalam penelitian ini ialah merk X-Power model XP 7000G. Gambar 2 memperlihatkan ionizer BBM yang digunakan dalam penelitian ini.

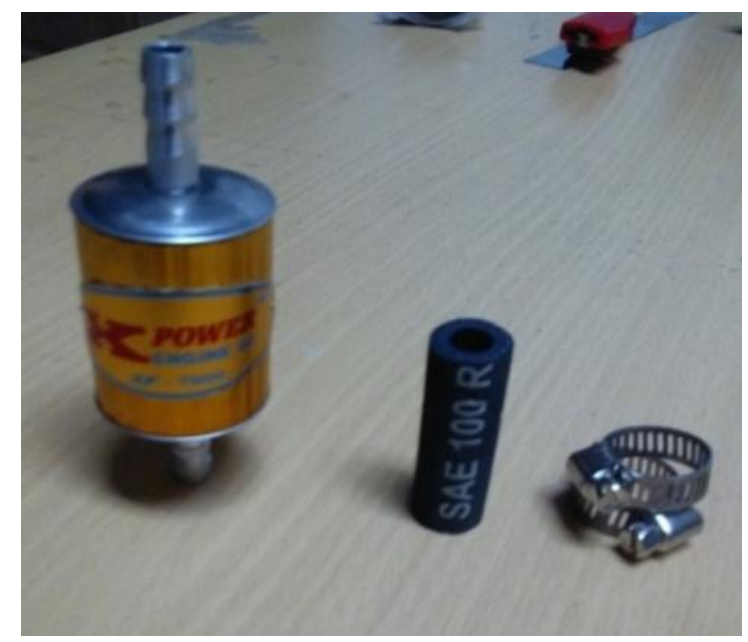

Gambar 2.

Ionizer Merk X-Power Model XP-7000G

Objek penelitian ini adalah mobil Suzuki Escudo tahun 1995. Pengambilan sampel dengan sistem karburator terutama pada mobil lama dimaksudkan agar penggunaan alat ionisasi ini menjadi alternatif dalam pengurangan emisi gas buang yang dihasilkan. Variasi penggunaan bahan bakar yaitu Premium, Pertalite dan Pertamax. Bensin merupakan campuran antara isooktana dan n-heptana. Kualitas bensin diketahui melalui nilai oktannya atau dikenal dengan Research Oktane Number (RON). Premium memiliki oktan 88 artinya $88 \%$ yang terdapat pada bahan bakar tersebut adalah iso-oktana sedangkan sisanya merupakan nheptana. Pertalite adalah RON90, sedangkan Pertamax adalah RON92. Gambar 3 memperlihatkan bahan bakar yang dicobakan 
dalam variasi penelitian ini, sedangkan Gambar 4 menunjukkan pemasangan ionizer BBM di mobil percobaan.

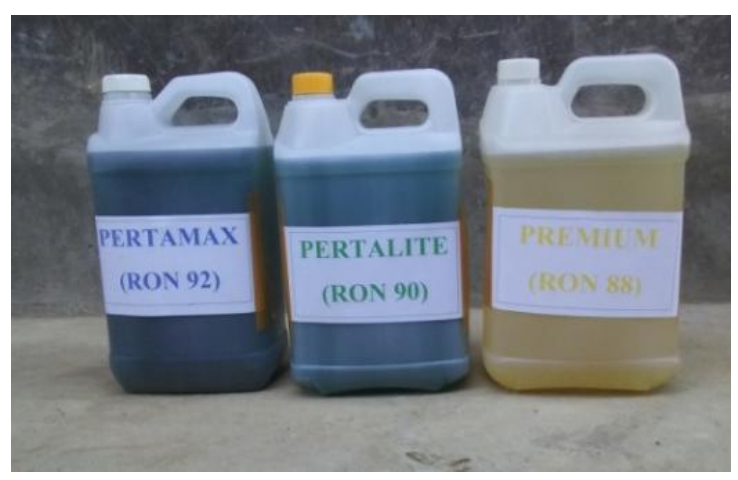

Gambar 3. Jenis Bahan Bakar

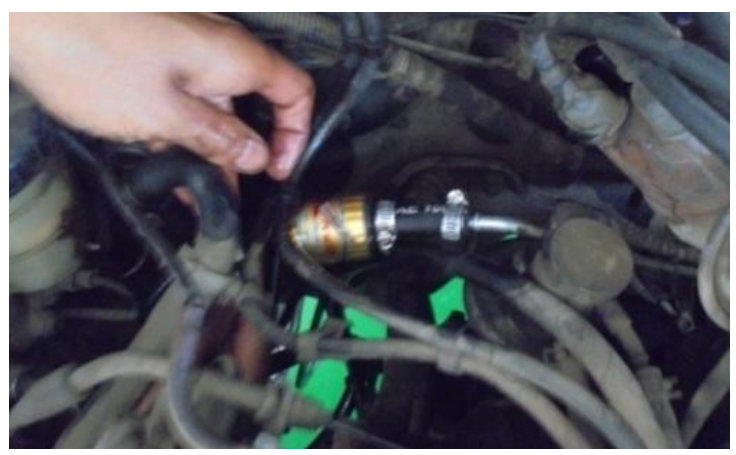

Gambar 5.

Pemasangan lonizer BBM pada Sampel Mobil

\subsection{Metode Pengujian Emisi}

Pengujian emisi dilakukan dengan SNI 197118.1-2005. Standar ini mengatur cara penguji kendaraan bermotor untuk kategori $M$, $\mathrm{N}$ dan $\mathrm{O}$ yang memiliki penggerak penyalaan cetus api pada kondisi idle. Kondisi idle merupakan kondisi saat kinerja mesin dalam keadaan diam atau dikenal juga dengan langsam. Putaran mesin pada kondisi idle adalah 800-1000 RPM (Rotation per minute). Pengulangan pada pengujian ini dilakukan pada saat pengukuran sebanyak tiga kali untuk memperoleh rata-rata pada tiap bahan bakar yang diuji. Efektivitas dilihat dengan membandingkan hasil pengujian sebelum dan sesudah dipasang ionizer BBM pada mobil yang sama.

\subsection{Analisa Data}

Metode analisis yang digunakan dalam penelitian ini adalah deskriptif untuk memperoleh fenomena dari data hasil penelitian. Metode analisis deskriptif adalah ditujukan untuk mendapatkan gambaran mengenai pengaruh suatu variable terhadap gejala atau keadaan yang divariasikan dalam suatu penelitian (Nazir [11]). Dalam penelitian ini, analisis deskriptif diaplikasikan untuk mendapatkan pengaruh penggunaan ionizer BBM terhadap variasi bahan bakar. Parameter gas yang diperiksa adalah $\mathrm{CO}$ dan $\mathrm{HC}$. Hubungan antara penggunaan ionizer BBM dan emisi yang dihasilkan digambarkan dalam diagram dan grafik.

\section{ANALISIS DAN PEMBAHASAN}

Dari hasil pengujian yang telah dilakukan mengenai pengaruh ionizer BBM dengan 
variasi bahan bakar (Premium, Pertalite, Pertamax) terhadap kadar emisi gas CO dan HC pada sampel mobil yang diuji. Hasil ratarata uji emisi dapat dilihat pada Gambar 6.

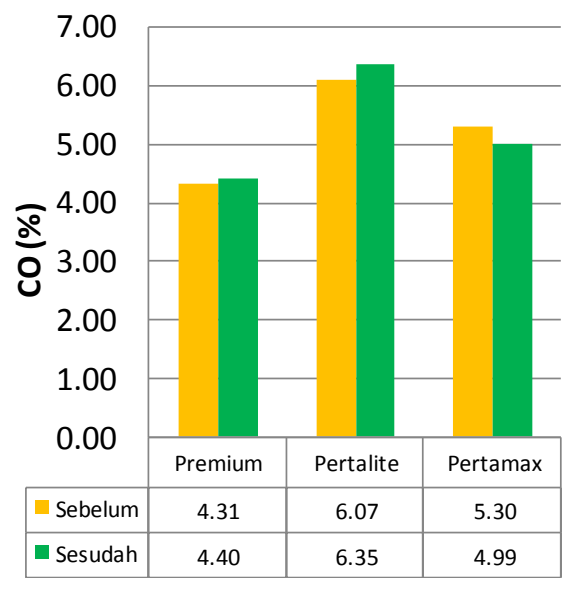

Gambar 6.

Grafik Pengaruh lonizer BBM Terhadap Emisi Gas CO

Berdasarkan Gambar 6 di atas, emisi gas CO dengan penggunaan jenis bahan bakar Premium menghasilkan emisi CO sebesar $4,31 \%$ (sebelum dipasang ionizer BBM). Setelah dipasang lonizer BBM emisi gas CO yang dihasilkan adalah $4,40 \%$ sehingga terjadi peningkatan emisi gas $\mathrm{CO}$ sebesar 0,09\% dibanding tidak memakai ionizer BBM. Penggunaan ionizer BBM dengan bahan bakar jenis Pertalite menghasilkan emisi CO sebesar 6,07 \% (sebelum dipasang ionizer BBM). Setelah dipasang ionizer BBM emisi gas CO yang dihasilkan adalah 6,35\% sehingga terjadi peningkatan emisi gas $\mathrm{CO}$ sebesar 0,28\% dibanding tidak memakai ionizer BBM. Dengan penggunaan bahan bakar berupa pertamax menghasilkan emisi CO sebesar 5,30\% (sebelum dipasang ionizer BBM). Setelah dipasang ionizer BBM emisi gas CO yang dihasilkan adalah 4,99\% sehingga terjadi penurunan emisi gas $\mathrm{CO}$ sebesar $0,31 \%$ dibanding tidak memakai ionizer BBM.

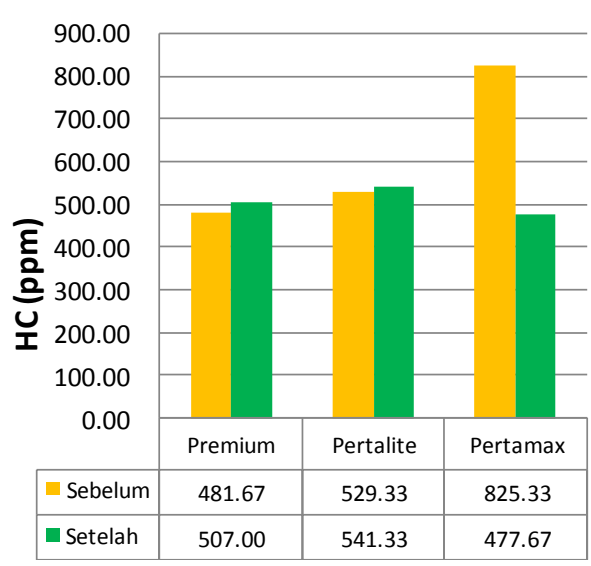

Gambar 7.

Grafik Pengaruh lonizer BBM Terhadap Emisi Gas HC

Berdasarkan Gambar 7 emisi gas HC dengan penggunaan jenis bahan bakar berupa Premium menghasilkan emisi HC sebesar 481,67 ppm (sebelum dipasang ionizer BBM). Setelah dipasang ionizer BBM emisi gas $\mathrm{HC}$ yang dihasilkan adalah 507,00 ppm sehingga terjadi peningkatan emisi HC sebesar 25,33 ppm dibanding tidak memakai ionizer BBM. Penggunaan jenis bahan bakar berupa 
Pertalite menghasilkan emisi HC sebesar 529,33 ppm (sebelum dipasang ionizer BBM). Setelah dipasang ionizer BBM emisi gas HC yang dihasilkan adalah 541,33 ppm sehingga terjadi peningkatan emisi HC sebesar 12,00 ppm dibanding tidak memakai ionizer BBM. Penggunaan jenis bahan bakar berupa Pertamax menghasilkan emisi HC sebesar 825,33 ppm (sebelum dipasang ionizer BBM). Setelah dipasang ionizer BBM emisi gas HC yang dihasilkan adalah 477,67 ppm sehingga terjadi penurunan emisi HC sebesar 347,66 ppm dibanding tidak memakai ionizer BBM. Penggunaan jenis bahan bakar harus sesuai dengan spesifikasi mesin kendaraan. Hal tersebut dapat mempengaruhi kinerja pada mesin kendaraan. Selain itu, kriteria rasio kompresi kendaraan juga perlu diperhatikan [9]. Bahan bakar Premium dengan nilai oktan 88 ditujukan untuk kendaraan dengan rasio kompresi maksimal 9, sedangkan Pertalite dan Pertamax untuk rasio 9 hingga 10.

Berdasarkan pada hasil penelitian, terlihat bahwa penggunaan ionizer BBM dengan bahan bakar Pertamax dapat menurunkan emisi CO sebesar $0,31 \%$ dan $\mathrm{HC}$ sebesar $347,66 \%$.

Berdasarkan data $\mathrm{CO}$ dan $\mathrm{HC}$ diatas dapat diketahui adanya pengaruh penggunaan alat ionisasi terhadap pembakaran. Pembakaran sempurna pada isooktana membentuk karbondioksida dan uap air. Sedangkan pembakaran tidak sempurna membentuk karbon monoksida dan uap air. Reaksi pembakaran sempurna adalah $\mathrm{C}_{8} \mathrm{H}_{18}+12,5$ $\mathrm{O}_{2}$ menghasilkan $8 \mathrm{CO}_{2}+9 \mathrm{H}_{2} \mathrm{O}$, dan menghasilkan nilai kalor sebesar $-5460 \mathrm{Kj}$. Sedangkan pada reaksi pembakaran tidak sempurna adalah $\mathrm{C}_{8} \mathrm{H}_{18}+8,5 \quad \mathrm{O}_{2}$ menghasilkan $8 \mathrm{CO}+9 \mathrm{H}_{2} \mathrm{O}$ dan menghasilkan nilai kalor sebesar -2924,4 Kj. Setelah mengalami proses ionisasi, ikatan rantai karbon berubah dari siklik (tertutup) menjadi alifatik (terbuka), sehingga oksigen yang terikat lebih banyak sebelum melewati ionizer. Pembakaran tak sempurna menghasilkan lebih sedikit kalor. Jadi, pembakaran tak sempurna mengurangi efisi bahan bakar.

\section{KESIMPULAN}

Berdasarkan hasil penelitian dapat disimpulkan bahwa :

1. Efektivitas penggunaan ionizer BBM pada mobil sistem karburator terhadap emisi gas $\mathrm{CO}$ dan $\mathrm{HC}$ dipengaruhi oleh penggunaan jenis bahan bakar.

2. Efektivitas terbaik diperoleh dengan penggunaan bahan bakar jenis pertamax. Emisi CO dapat turun sebesar 0,31\% 
dan penurunan emisi HC sebesar 347,66 ppm. Adanya peningkatan efisiensi bahan bakar yang digunakan maka nilai kalor yang didapatkan menjadi lebih besar sehingga emisi $\mathrm{CO}$ dan $\mathrm{HC}$ menjadi turun.

3. Secara keseluruhan, ionizer BBM memperlihatkan pengaruh terhadap penurunan emisi gas buang karbon monoksida dan hidrokarbon, namun dengan efektivitas yang relatif rendah.

\section{DAFTAR PUSTAKA}

[1] Gunawan, G., "Tingkat Pencemaran Udara Debu dan Timbal di Lingkungan Gerbang Tol," Jurnal Jalan dan Jembatan, vol. 32 no 2, pp. 115-124, 2015.

[2] Yahya, W., "Variasi Penggunaan Ionizer dan Jenis Bahan Bakar terhadap Kandungan Gas Buang Kendaraan," Jurnal Autindo Politeknik Indonusa Surakarta, vol. 1 no. 2, pp. 48-53, 2015.

[3] Ismiyati, Marlita, D., Saidah, D., "Pencemaran Udara Akibat Emisi Gas Buang Kendaraan Bermotor," Jurnal Manajemen Transportasi dan Logistik (JMTransLog), vol. 1 no. 3, pp. 241-248, 2014.
[4] Dahlan, E. N., "Dampak Pencemaran Udara terhadap Kesehatan Manusia dan Beberapa Komponen Sumberdaya Alam," Media Konservasi, vol. II no. 2, pp. 39-44, 1989.

[5] Budiyono, A., "Pencemaran Udara: Dampak Pencemaran Udara pada Lingkungan," Berita Dirgantara, vol. 2 no.1, pp. 21-27, 2001.

[6] Sugiarti, "Gas Pencemar Udara dan Pengaruhnya Bagi Kesehatan Manusia," Jurnal Chemica, vol. 10 no. 1pp. 50-58, 2009.

[7] https://xpower-ionizer.com/xpower-prinsipkerjanya, diakses Januari 2019.

[8] Santoso, B. Kaji Eksperimen Perbandingan Konsumsi Bahan Bakar Sistem Injeksi dan Karburator dengan Variabel Bobot Pengendara. Publikasi IImiah. Surakarta: Universitas Muhammadiyah Surakarta, 2016.

[9] Mulyono, S., Gunawan, Maryanti, B., "Pengaruh Penggunaan dan Perhitungan Efisiensi Bahan Bakar Premium dan Pertamax terhadap Unjuk Kerja Motor Bahan Bakar Bensin," Jurnal Teknologi Terpadu, vol. 2 no.1, pp. 28-35, 2014.

[10] Luthfi, M., Ahmad R.,D., Setiyo, M., 
Infomatek Volume 21 Nomor 1 Juni $2019: 61$ - 68

Munahar, S., "Uji Komposisi Bahan Bakar

dan Emisi Pembakaran Pertalite dan

Premium," Jurnal Teknologi Universitas

Muhammadiyah Jakarta, vol. 10 no. 1, pp.

67-72, 2018.
[11] Nazir, M. Metode Penelitian. Cetakan ke-9. Bogor: Ghalia Indonesia. 2014. 